\title{
内標準法を用いる誘導結合プラズマ発光分析法による 重水-軽水混合溶液中の微量ホウ素の定量
}

\author{
加藤 金治 ${ }^{\circledR}$, 高島教一郎*
}

(1989 年: 9 月 4 日受理)

\begin{abstract}
重水 $\left(\mathrm{D}_{2} \mathrm{O}\right)$ - 軽水 $\left(\mathrm{H}_{2} \mathrm{O}\right)$ 混合溶液試料中の微量ホウ素の定量法として $\mathrm{Cu}$ を内標準元素とする ICP-AES を開発した. 実試料重水 $16 \mathrm{ml}$ を $20 \mathrm{ml}$ メスフラスコに採取し, これに $\mathrm{Cu} 200 \mu \mathrm{g}$ を添加し た後, 軽水で定容し測定用試料とした。検量には軽水調製の $\mathrm{Cu}$ 内標準検量線用溶液を用いた。検量線 は $0.01 \sim 100 \mu \mathrm{g} \mathrm{B} / \mathrm{ml}$ の範囲で直線であり, バックグラウンド等価濃度（BEC）は $0.17 \mu \mathrm{g} \mathrm{B} / \mathrm{ml}$, 検出 限界 $(3 \sigma, n=10)$ は $1.50 \mathrm{ng} \mathrm{B} / \mathrm{ml}$ が得られた。ホウ素 $0.01,0.1,1,5$ 及び $10 \mu \mathrm{g} / \mathrm{ml}$ を含む重水 $80 \mathrm{vol} \%$ 軽水 $20 \mathrm{vol} \%$ 溶液を 10 回繰り返し測定したときのホウ素定量値の精度は相対標準偏差でそれぞれ 20, 7.5，3.5，3.0 及び $1.0 \%$ であった。本法を原子炉級重水中のホウ素の定量に適用した。 又，ホウ素の ほかには, $\mathrm{Si}$ 及び $\mathrm{Al}$ も $\mathrm{Cu}$ を内標準元素として, 更に, $\mathrm{Mg}, \mathrm{Cd}$ 及び $\mathrm{Mn}$ は $\mathrm{Cr}$ を内標準元素とする ことにより定量できることが分かった。
\end{abstract}

\section{1 緒言}

原子炉に減速，冷却材として用いられる重水中の不純 物元素は厳密に管理される。特に熱中性子吸収断面積が 大きいという核的特性から, 不純物ホウ素は納入仕様で はクルクミン吸光光度法（検出限界 $0.002 \mu \mathrm{g} \mathrm{B} / \mathrm{ml}$ ) で 検出されないことと規定されている，又，重水は国際規 制物質であり, その撖重な計量管理が要求されるので, 広い重水濃度範囲の標準試料が必要であり, 標準重水作 製の要請面からも，その高感度分析が重要である。ホウ 素の高感度定量法として吸光光度法 ${ }^{1) 2}$, 蛍光法 ${ }^{1) ~-3), ~}$ フレーム光度法 ${ }^{(1) 4}$, 及び質量分析法5)などが常用されて いるが, 感度や精度が不十分であったり, 妨害も多く, 分離法を併用したり定量操作条件が厳しかったり煩雑な ために, 多数の試料を扱う日常分析には不適であった。 又, 重水の純度測定は比重測定法が基準になっており， 直接重水中のホウ素を定量した例として, $\mathrm{Ag}$ あるいは $\mathrm{Cu}$ 電極スパーク発光分析法(6)7 で $0.1 \mathrm{ppm}$ 以下のホウ 素を，更に，重水に可然性毒物として添加した 0.3〜20 ppm レベルのホウ素を同位体希釈質量分析法, クルク ミン吸光光度法なゼ各種の方法 ${ }^{8)}$-10) で定量した報告が ある。なお，試料調製法としては，重水を蒸発乾固し， 軽水に置き換える方法が簡便で優れているが，ホウ素に

*日本原子力研究所東海研究所化学部分析センター : 319-11 茨城県那珂郡東海村
ついては, 乾固操作による揮散損失という問題がある. 本報告では検出限界が低く，多元素も同時に定量でき るという利点をも考慮して, 重水溶液系を軽水置換せず ほぼそのまま噴霧試料とし, 検量には通常の軽水製の標 準溶液を用いる ICP-AES によるホウ素定量法を検討し た.その結果, $\mathrm{Cu}$ を内標準として用いることにより重 水と軽水の物性（主に粘度）差に起因する物理干渉（噴 霧量変化）を補正除去し得ることを見いだした。なお， 本法の検出限界は $0.0015 \mu \mathrm{g} \mathrm{B} / \mathrm{ml}$ で, 0.01 及び $10 \mu \mathrm{g}$ $\mathrm{B} / \mathrm{ml}$ 定量時における繰り返し精度はそれぞれ 20 及び $1.0 \%$ であった. 又, 同手法による $\mathrm{Si}, \mathrm{Al}, \mathrm{Mg}$ など他 不純物元素の定量結果も付記する.

\section{2 実験}

\section{$2 \cdot 1$ 試 薬}

検討に用いた重水, 軽水及び検量用ホウ素溶液など試 薬類は次の通りである.

標準重水: カナダ製重水 $(99.32 \mathrm{~mol} \%)$ を蒸留精製し たものを用いた。

精製軽水: 蒸留水をイオン交換法により精製し, 更に 石英製蒸留器により 2 回蒸留したもの $(\mathrm{B}<0.1 \mathrm{ppb})$ を用いた。

ホウ素標準溶液 $(B \quad \mathrm{mg} / \mathrm{ml})$ : 試薬特級のホウ酸約 $0.57 \mathrm{~g}$ を精製軽水に溶解し, $100 \mathrm{ml}$ とした. 使用に際 しては，この溶液を精製軽水で適宜希釈したものを用い 
た.

その他の試薬はすべて市販特級品をそのまま用い，木 ウ素以外の各元素標準溶液は適宜試薬及び高純度金属か ら調製して使用した。

\section{$2 \cdot 2$ 装}

使用した ICP-AES 装置は島津製作所製で次の各部か ら成る。

多元素同時測定型回折格子分光器 GEW-170P : 焦点 距離 $1.7 \mathrm{~m}$ のオフプレーンエバートマウンティング, 溝数 2160 本 $/ \mathrm{mm}$ の平面回折格子, 入口スリット幅 50 $\mu \mathrm{m}$, 出口スリット幅 $100 \mu \mathrm{m}$ 及び 1 : 1 スリット結像法 を採用しており, 逆線分散は $0.26 \mathrm{~nm} / \mathrm{mm}$ である.

高周波電源 ICPS- $2 \mathrm{H}: 27.12 \mathrm{MHz}$, 水冷 2 巻き銅負 荷コイル使用, 最大出力 $3 \mathrm{~kW}$ が得られる.

試料導入系: Meinhard 型ガラス製同軸ネブライ ザー, Scott 型ガラス製ダブルパススプレーチェン バー, 及び Fassel 型溶融石英製プラズマトーチで構成 される.

検出器 : 浜松ホトニクス製 $\mathrm{R} 300$ 光電子増倍管.

データ処理系: 島津 RE-10 にオリベッティ製 TC485 テレタイプライターを接続.

\section{$2 \cdot 3$ 操作法}

ICP 分析操作条件を Table 1 に示す. 試料重水中の ホウ素濃度を考慮すると，なるべく軽水による希釈率は 小さくしたい反面, 内標準元素の添加精度を考慮する 之，ある程度の希釈率が必要となる，その兼站合いか ら,ここでは $80 \mathrm{vol} \%$ 重水として検討することにし た。すなわち，試料重水 $16 \mathrm{ml}$ を $20 \mathrm{ml}$ メスフラスコ に採取し、これに内標準用 $\mathrm{Cu} 200 \mu \mathrm{g}$ を添加後, 軽水 で正確に標線まで希釈する。このようにして調製した重

Table 1 ICP analytical conditions

\begin{tabular}{|c|c|c|c|}
\hline \multicolumn{2}{|c|}{ Incident power } & \multicolumn{2}{|l|}{$1.6 \mathrm{~kW}$} \\
\hline \multicolumn{2}{|c|}{ Reflected power } & \multicolumn{2}{|l|}{$<3 \mathrm{~W}$} \\
\hline \multicolumn{2}{|c|}{ Ar outer gas flow rate } & \multicolumn{2}{|c|}{$10.5 \mathrm{l} / \mathrm{min}$} \\
\hline \multicolumn{2}{|c|}{ Ar intermediate gas flow rate } & \multicolumn{2}{|c|}{$1.0 \mathrm{l} / \mathrm{min}$} \\
\hline \multicolumn{2}{|c|}{ Ar carrier gas flow rate } & \multicolumn{2}{|c|}{$1.2 \mathrm{l} / \mathrm{min}$} \\
\hline \multicolumn{2}{|c|}{ Observation height } & \multicolumn{2}{|c|}{$16 \mathrm{~mm}$ above load coil } \\
\hline \multirow{2}{*}{\multicolumn{4}{|c|}{$\begin{array}{l}\text { Integration time } \\
\text { Spectral lines }(\mathrm{nm})\end{array}$}} \\
\hline & & & \\
\hline B I & 249.77 & $\mathrm{Cu} \mathrm{I}$ & 324.75 \\
\hline $\mathrm{Si} \quad \mathrm{I}$ & 251.61 & $\mathrm{Al} \mathrm{I}$ & 308.21 \\
\hline Mg II & 279.55 & Cd II & 226.50 \\
\hline Mn II & 257.61 & Cr II & 267.71 \\
\hline
\end{tabular}

水試料を Table 1 の条件で ICP 分析し, 得られたホウ 素の発光強度 $\left(I_{\mathrm{B}}\right)$ 及び内標準 $\mathrm{Cu}$ の発光強度 $\left(I_{\mathrm{Cu}}\right)$ より $I_{\mathrm{B}} / I_{\mathrm{Cu}}$ 比を求め, 更に, 通常の軽水製の検量用標 準溶液を用いてあらかじめ作成したホウ素濃度と $I_{\mathrm{B}} /$ $I_{\mathrm{Cu}}$ 比亡の関係線からホウ素濃度を求める.

なお，検討したその他不純物元素 $(\mathrm{Si}, \mathrm{Al}, \mathrm{Mg}, \mathrm{Cd}$ 及び $\mathrm{Mn})$ 及び内標準元素 $(\mathrm{Cr})$ のスペクトル線も Table 1 に揭げる。

\section{3 実験結果及び考察}

\section{$3 \cdot 1$ 重水濃度による試料噴霧量の変化}

重水一軽水混合溶液中の重水濃度に対する試料噴霧量 (吸引重量) の変化を Fig. 1 に示す. 軽水の試料噴霧量 $(3.4 \mathrm{~g} / \mathrm{min})$ を 100 としし，10〜100 vol\% の重水を噴霧 した場合の試料噴霧量を測定したものである. 更に，試 料溶夜の密度から吸引体積に換算した結果及び混合溶液 の粘度の文献値 ${ }^{11)}$ も合わせて示してある. 混合溶液中 の重水濃度が増すと共に，試料噴霧量は減少する。これ は, 主に重水濃度の増加と共に, 混合溶液の粘度が増加 することに起因すると考えられる.

\section{$3 \cdot 2$ 発光強度の重水濃度依存性}

Fig. 2 に, ホウ素 $1.0 \mu \mathrm{g} / \mathrm{ml}$ を含む重水-軽水混合溶 液について, ホウ素の発光強度に対する重水濃度の影響 を示す. Fig. 2 には, 発光強度を試料溶液の吸引重量及 び吸引体積の変化率で補正した結果も示してある。ここ

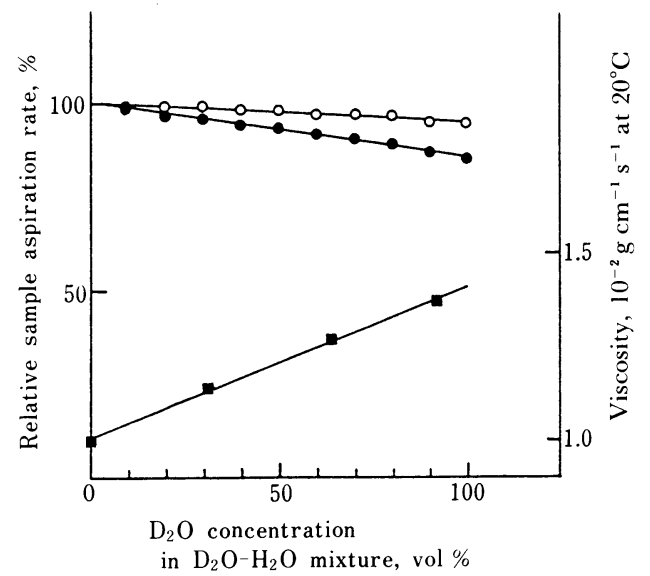

Fig. 1 Effect of $\mathrm{D}_{2} \mathrm{O}$ concentration on the sample aspiration rate

$\bigcirc$ : aspiration rate in weight; $:$ aspiration rate in volume; $\mathbf{D}$ : viscosity. The aspiration rate for pure $\mathrm{H}_{2} \mathrm{O}$ was defined as 100 . 


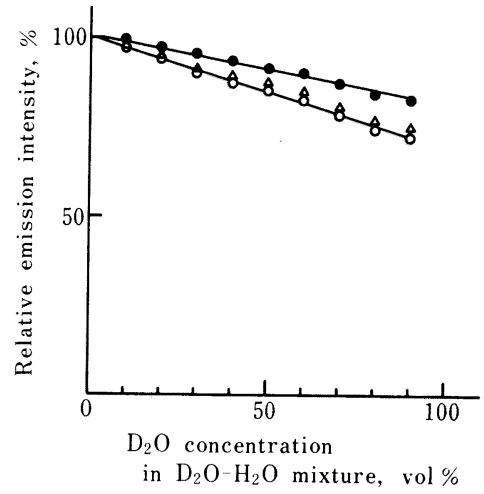

Fig. 2 Effect of $\mathrm{D}_{2} \mathrm{O}$ concentration on the boron emission intensity

$\bigcirc$ : observed intensity; $\triangle$ : intensity corrected for aspiration weight; : intensity corrected for aspiration volume. The emission intensity of $1.0 \mu \mathrm{g} / \mathrm{ml} \mathrm{B}$ in pure $\mathrm{H}_{2} \mathrm{O}$ was defined as 100.

で明らかなように, 重水濃度が増すに従い, 発光強度は 減少する. その原因の一つとして, Fig. 1 に示したネブ ライザーの試料噴霧量の減少が挙げられるが, 発光強度 の変化に対する重量及び体積補正法が無効であることか ら, ICP 中への試料エアロゾルの導入量やエアロゾル の粒径の違いによる励起効率の減少がより大きな原因之 考えられる.

\section{$3 \cdot 3$ 内標準法の適用}

$3 \cdot 1$ 及び $3 \cdot 2$ で述べたように, ネブライザーの試料噴 霧量及び ICP 中での励起効率の溶液物性依存性（主に 粘度依存性) が顕著であるため, 内標準法の適用が有効 と考えて，この物理干渉の補正法を検討したＩCP 分 析での内標準元素は種々検討されているが12) 23)，ホウ 素の定量において最適な内標準元素を選択するには，少 なくとも次の 4 条件を満たすここが必要である。すな わち，(1)試料重水中に含まれないか，あるいは含まれ ていても極微量の元素，（2）ホウ素にスペクトル干渉を 与えない元素, (3) 実用分析上, 発光強度の測定がホウ 素と同時に行える元素，(4)内標準線として，ホウ素の 発光線 (249.77 $\mathrm{nm}$ の原子線) の励起挙動と類似した励 起挙動の発光線が利用できる元素, 以上の観点から内標 準元素として Gu を選択した。ここで，検討に用いた標 準重水中の $\mathrm{Cu}$ 濃度は $10 \mathrm{ppb}$ 以下であることを ICP 写 真測光法などによりあらかじめ確認した。

ホウ素 $200 \mu \mathrm{g}$ を含む重水に Cu $200 \mu \mathrm{g}$ を内標準とし

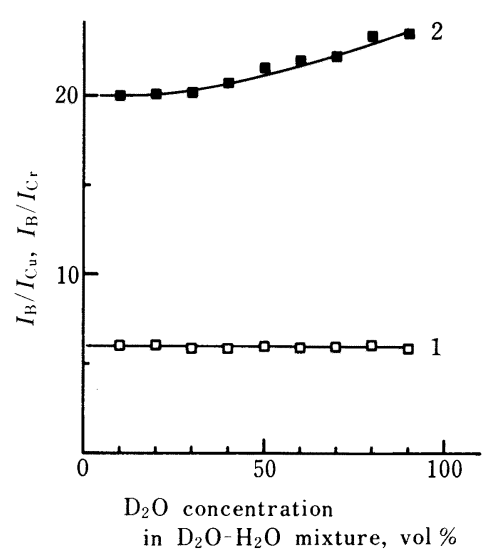

Fig. 3 Effect of $\mathrm{D}_{2} \mathrm{O}$ concentration on the emission intensity ratios of $I_{\mathrm{B}} / I_{\mathrm{Cu}}$ and $I_{\mathrm{B}} / I_{\mathrm{Cr}}$

$\square: I_{\mathrm{B}} / I_{\mathrm{Cu}} ; \quad: I_{\mathrm{B}} / I_{\mathrm{Cr}} ; I_{\mathrm{B}}, \quad I_{\mathrm{Cu}}$ and $I_{\mathrm{Cr}}$ : emission intensity of $10 \mu \mathrm{g} / \mathrm{ml} \mathrm{B}, \mathrm{Cu}$ and $\mathrm{Cr}$, respectively

て添加し, 全量を $20 \mathrm{ml}$ に軽水で希釈した後, ホウ素 の発光強度 $\left(I_{\mathrm{B}}\right)$ 及び $\mathrm{Cu}$ の発光強度 $\left(I_{\mathrm{Cu}}\right)$ を測定し た. Fig. 3 曲線 1 に, 重水-軽水混合溶液中の重水濃度 と $I_{\mathrm{B}} / I_{\mathrm{Cu}}$ 比をプロットした結果を示す。ここで明らか なように, 重水濃度によらず $I_{\mathrm{B}} / I_{\mathrm{Cu}}$ 比は一定值を示 し，ホウ素と $\mathrm{Cu}$ がこの種の物理干渉に関する挙動が同 一であり，ホウ素の定量に際して $\mathrm{Cu}$ が適していること が分かる.ここで，Cu の内標準線としては $324.75 \mathrm{~nm}$ の原子線を用いている. 更に重要なことは, どのような 重水濃度の重水一軽水混合溶液試料であっても, 本操作 法のように軽水で調製した Cu内標準検量線用溶液を用 いて定量が可能な点である.

又, Fig. 3 曲線 1 を得たのと同様な操作によって, $\mathrm{Cu}$ の代わりに後述のように $\mathrm{Mg}$, Cd 及び Mn に対し て有効に㗢いた Cr (II $267.71 \mathrm{~nm}$ ) を内標準として 200 $\mu \mathrm{g}$ 添加して得た結果を Fig. 3 曲線 2 に示す. $I_{\mathrm{B}} / I_{\mathrm{Cr}}$ 比 は重水濃度によって変わるので, Cr はホウ素定量時の 内標準元素としては不適当であることが分かった.

\section{$3 \cdot 4$ スペクトル干渉}

ICP-AES において，ホウ素の $249.77 \mathrm{~nm}$ 原子線に対 する $\mathrm{Fe}$ の $249.78 \mathrm{~nm}$ イオン線のスペクトル干渉が知ら れているが24) 29), これは Fe $1 \mathrm{ppm}$ がホウ素 $1.3 \mathrm{ppb}$ に相当する程度の干渉であり，ここでは分析に用いた他 の定量元素の発光線と同様に，ホウ素に対する妨害は問 題とならなかった. 


\section{$3 \cdot 5$ 検量線}

$2 \cdot 3$ の操作法に従い, 重水 $80 \mathrm{vol} \%$-軽水 $20 \mathrm{vol} \%$ 溶 液で得られる $I_{\mathrm{B}} / I_{\mathrm{Cu}}$ 比とホウ素濃度との関係曲線（内 標準検量線）は，ホウ素濃度 $0.01 \sim 100 \mu \mathrm{g} / \mathrm{ml}$ の範囲で 直線関係を示す. $1 \mu \mathrm{g} / \mathrm{ml}$ における $I_{\mathrm{B}} / I_{\mathrm{Cu}}$ 比の変動は $0.73 \pm 0.02$ であり，このこう配は軽水調製の検量線のそ れと極めてよく一致する。バックグラウンド等価濃度 (BEC) は $0.17 \mu \mathrm{g} / \mathrm{ml}$, 検出限界 $(3 \sigma, n=10)$ は 1.50 $\mathrm{ng} / \mathrm{ml}$ が得られた. 又, 軽水製検量線を用いて, ホウ素

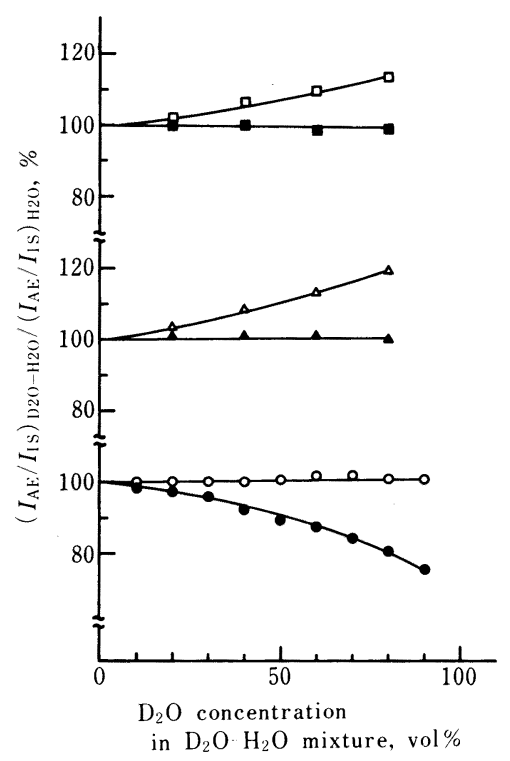

Fig. 4 Effect of $\mathrm{D}_{2} \mathrm{O}$ concentration on the ratio of $\left(I_{\mathrm{AE}} / I_{\mathrm{IS}}\right)_{\mathrm{D} 2 \mathrm{O}-\mathrm{H} 2 \mathrm{O}} /\left(I_{\mathrm{AE}} / I_{\mathrm{IS}}\right)_{\mathrm{H} 2 \mathrm{O}}$ $\square: I_{\mathrm{Si}} / I_{\mathrm{Cr}} ; \quad \square: I_{\mathrm{Si}} / I_{\mathrm{Cu}} ; \quad \Delta: I_{\mathrm{Al}} / I_{\mathrm{Cr}} ; \quad \Delta$
$I_{\mathrm{Al}} / I_{\mathrm{Cu}} ; \quad \bigcirc: I_{\mathrm{Mg}} / I_{\mathrm{Cr}} ; \quad: I_{\mathrm{Mg}} / I_{\mathrm{Cu}} ; \quad I_{\mathrm{AE}}:$ $I_{\mathrm{Al}} / I_{\mathrm{Cu}} ; \bigcirc: I_{\mathrm{Mg}} / I_{\mathrm{Cr}} ; \quad: I_{\mathrm{Mg}} / I_{\mathrm{Cu}} ; \quad I_{\mathrm{AE}}:$
emission intensity of analyte element; $I_{\mathrm{IS}}$ : emission intensity of internal standard element. The emission intensity ratio of $10 \mu \mathrm{g} / \mathrm{ml}$ analyte element to $10 \mu \mathrm{g} / \mathrm{ml}$ internal standard element in pure $\mathrm{H}_{2} \mathrm{O}$ was defined as 100 .
$0.01,0.1 ， 1,5$ 及び $10 \mu \mathrm{g} / \mathrm{ml}$ を含む重水 $80 \mathrm{vol} \%$-軽 水 $20 \mathrm{vol} \%$ 溶液を 10 回繰り返し測定したときのホウ素 定量值の繰り返し精度は相対標準偏差でそれぞれ 20, $7.5,3.5,3.0$ 及び $1.0 \%$ であった.

\section{3・6 他不純物元素の定量}

ホウ素分析と同様な操作に従って, $\mathrm{Si}, \mathrm{Al}, \mathrm{Mg}, \mathrm{Cd}$ 及び Mnの内標準法による同時定量も試みた。 Fig. 4 にその代表例を示すように，内標準としての有効性から $\mathrm{Si}$ 及び $\mathrm{Al}$ には $\mathrm{Cu}$ を， $\mathrm{Mg}, \mathrm{Cd}$ 及び $\mathrm{Mn}$ には Crを内 標準元素として採用した。得られた検出限界 (3 $\sigma$, $n=10 ）$ は Si 18.1, Al 16.7, $\mathrm{Mg} 0.096$, Cd 3.9 及び Mn $0.64 \mathrm{ng} / \mathrm{ml}$ である. 実試料についての分析結果は Table 2 にまとめて示す。なお, Ni (II $231.60 \mathrm{~nm}$ ), Co (II $238.89 \mathrm{~nm})$ 及び Ti (II $334.94 \mathrm{~nm})$ については $\mathrm{Cr}$ 及び $\mathrm{Cu}$ 内標準法による同様な補正法は適用できな かった。

\section{$3 \cdot 7$ 実試料への適用}

実試料への適用に先立って, 標準重水に既知量の各元 素を添加してそれぞれ回収率を求めたところ, 97〜 104\% であった. 本法を 5 種類の未精製, 精製原子 炉級重水試料に適用して得られた分析結果を Table 2 に示す。ホウ素, $\mathrm{Si}, \mathrm{Al}$ 及び $\mathrm{Mg}$ 以外はいずれの試料 からも検出されなかった。試料 $\mathrm{E}$ は試料 D を蒸留精 製30) したものであるが， $\mathrm{Si}, \mathrm{Al}$ 及び $\mathrm{Mg}$ の約 $60 \%$ が 除去されるものの，ホウ素には精製効果のないこと， 又, 試料 $\mathrm{C}$ は長期間ガラスアンプル詰めされていたも ので，ホウ素上 $\mathrm{Mg}$ のアンプルからの溶出が考えられ ること, 更に, ホウ素と Si については環境からの活染 も考えられることなどが分かった。

以上, 本法によれば問題となる試料噴霧量の変化とい う物理干渉を補正でき, 軽水で調製した Cu内標準検量 線用溶液を用いてよ゙のような重水濃度の重水一軽水混合

Table 2 Determination of boron and other impurity elements in reactor grade heavy water samples

\begin{tabular}{|c|c|c|c|c|c|c|c|c|}
\hline \multirow{2}{*}{ Sample } & \multirow{2}{*}{$\mathrm{B}, \mathrm{ppm}$} & \multirow{2}{*}{ R.S.D., \% } & \multicolumn{6}{|c|}{ Other impurities, ppm } \\
\hline & & & $\mathrm{Si}$ & R.S.D., \% & $\mathrm{Al}$ & R.S.D., \% & $\mathrm{Mg}$ & R.S.D., \% \\
\hline $\mathrm{A}^{\mathrm{a})}$ & $0.27_{9} \pm 0.01_{4}$ & 5.0 & $1.4_{7} \pm 0.0_{5}$ & 3.4 & $0.3_{2} \pm 0.0_{2}$ & 6.3 & $0.009 \pm 0.004$ & 44.4 \\
\hline $\mathrm{B}^{\mathbf{a})}$ & $0.01_{0} \pm 0.00_{2}$ & 20.0 & $1.6_{9} \pm 0.0_{5}$ & 3.0 & $0.5_{3} \pm 0.0_{2}$ & 3.8 & $0.016 \pm 0.005$ & 31.3 \\
\hline $\mathrm{C}^{\mathrm{b}) \mathrm{c})}$ & $0.35_{6} \pm 0.01_{6}$ & 4.5 & $0.8_{5} \pm 0.0_{3}$ & 3.5 & $0.3_{8} \pm 0.0_{2}$ & 5.3 & $0.027 \pm 0.005$ & 18.5 \\
\hline $\mathrm{D}^{\mathrm{a})}$ & $0.01_{0} \pm 0.00_{2}$ & 20.0 & $1.8_{5} \pm 0.0_{6}$ & 3.2 & $0.9_{6} \pm 0.0_{3}$ & 3.1 & $0.009 \pm 0.004$ & 44.4 \\
\hline$E^{b)}$ & $0.01_{0} \pm 0.00_{2}$ & 20.0 & $0.8_{0} \pm 0.0_{3}$ & 3.8 & $0.3_{1} \pm 0.0_{2}$ & 6.5 & $0.004 \pm 0.002$ & 50.0 \\
\hline
\end{tabular}

a) unpurified; b) purified; c) ampouled; R.S.D. (relative standard deviation) is based on five replicate analyses. 
溶液試料中のホウ素も $3 \cdot 5$ に示した精度で容易に定量 できること, 又, $\mathrm{Si}$ 及び $\mathrm{Al}$ も同様に $\mathrm{Cu}$ を内標準とし て, 更に, $\mathrm{Mg}, \mathrm{Cd}$ 及び $\mathrm{Mn}$ は $\mathrm{Cr}$ を内標準とするこ とにより定量できることを明らかにした。

終わりに，本研究に際しご支援をいただいた日本原子力 研究所研究炉技術課の吉島哲夫氏並びに近藤忠美氏に深謝 致します。

\section{文献}

1）無機応用比色分析編集委員会編: “無機応用比色 分析”, 第 1 巻, p. 247 (1980), (共立出版).

2) J. Aznarez, A. Bonilla, J. C. Vidal : Analyst (London), 108, 368 (1983).

3) J. M. Mir, C. Martinez: Talanta, 33, 541 (1986).

4) J. R. Castillo, J. M. Mir, C. Martinez, C. Bendicho: Analyst (London), 110, 1435 (1985).

5) N. L. Duchateau, A. Verbruggen, F. Hendrickx, P. De Bièvre: Anal. Chim. Acta, 196, 41 (1987).

6) R. J. Webb : United Kingdom Atomic Energy Authority Report, AERE-AM-8 (1959).

7) J. Artaud, J. Normand, R. Vie : Centre d' Etudes Nucléaires de Saclay (France) Report, CEA-1927 (1961).

8) Y. Wada, S. Takahashi, K. Onishi, T. Tsuboya : Power Reactor and Nuclear Fuel Development Corporation (Japan) Report, PNCT-831-78-02 (1978).

9) R. S. Chitre, V. R. Joshi, C. S. P. Iyer : Government of India Atomic Energy Commission Report, BARC-1197 ( 1983 ).

10) N. L. Elliot, P. L. J. Faught, L. W. Green, J. Gulens, T. H. Longhurst, J. P. Mislan, P. K. Leeson, E. C. Davey : Atomic Energy of Canada Limited Report, AECL-8269 (1984).

11) J. Timmermans: "The Physico-chemical Constants of Binary Systems in Concentrated Solutions", Vol. 4, pp. 471, 472 (1960), (Interscience Pub., New York).

12) W. B. Barnett, V. A. Fassel, R. N. Kniseley: Spectrochim. Acta, 23B, 643 (1968); 25B, 139 (1970).

13）内田 弘, 根岸良吉, 山崎龍一, 今井雄一: 分析化 学, 28, 244 (1979).

14) E. D. Salin, G. Horlick : Anal. Chem., 52, 1578 (1980).

15) H. Uchida, Y. Nojiri, H. Haraguchi, K. Fuwa : Anal. Chim. Acta, 123, 57 (1981).

16) 遠藤芳秀, 坂尾則隆: 分析化学, 30, 433 (1981).

17) G. J. Schmidt, W. Slavin : Anal. Chem., 54, 2491 (1982).

18) S. D. Hartenstein, H. M. Swaidan, G. D. Christian : Analyst (London), 108, 1323 (1983).

19) G. F. Wallace: At. Spectrosc., 5, 5 (1984).

20) A. Lorber, Z. Goldbart, A. Harel, E. Sharvit, M. Eldan : Spectrochim. Acta, 41B, 105 (1986).

21) J. R. Sedcole, J. Lee, M. W. Pritchard :
Spectrochim. Acta, 41B, 227 ( 1986 ).

22) M. H. Ramsey, M. Thompson: J. Anal. At. Spectrom., 2, 497 (1987).

23) 山本和子, 米谷 明, 内野興一: 日本分析化学会 第 37 年会講演要旨集, p. 1230 (1988).

24) 秋吉孝則, 塚本多香子: 分析化学, 27, 85 (1978).

25) G. F. Wallace: At. Spectrosc., 2, 61 (1981).

26) M. A. B. Pougnet, M. J. Orren : Intern. J. Environ. Anal. Chem., 24, 253 (1986).

$27)$ L. Xu, Z. Rao : Fresenius' Z. Anal. Chem., 325, 534 (1986)

$28)$ B. A. Zarcinas, B. Cartwright : Analyst (London), 112, 1107 (1987).

29) I. Novozamsky, R. van Eck, J. J. van der Lee, V. J. G. Houba, G. O. Ayaga : At. Spectrosc., 9, 97 (1988).

30）郡司勝文, 大内 操, 渡部和男, 小森卓二: 私信 (1986).

$$
\hat{n}
$$

Determination of traces of boron in mixed solutions of heavy water and light water by ICP-AES with internal standardization. Kaneharu KATO and Kyoichiro TAкаsнima (Analytical Chemistry Laboratory, Department of Chemistry, Tokai Research Establishment, Japan Atomic Energy Research Institute, Tokaimura, Naka-gun, Ibaraki 319-11)

The determination of $\mathrm{B}$ in mixed solutions of heavy water $\left(\mathrm{D}_{2} \mathrm{O}\right)$ and light water $\left(\mathrm{H}_{2} \mathrm{O}\right)$ by ICP-AES using $\mathrm{Cu}$ as an internal standard element (ISE) was investigated. Real heavy water samples of $16 \mathrm{ml}$ were pipetted respectively into volumetric flasks of $20 \mathrm{ml}$ and diluted to the mark with light water after the addition of $200 \mu \mathrm{g} \mathrm{Cu}$. In calibration, Cu internal standard calibration solutions prepared with light water were used. The obtained linear dynamic range, background equivalent concentration (BEC), and detection limit $(3 \sigma, n=10)$ were 0.01 to $100 \mu \mathrm{g} \mathrm{B} / \mathrm{ml}, 0.17 \mu \mathrm{g} \mathrm{B} / \mathrm{ml}$ and $1.50 \mathrm{ng}$ $\mathrm{B} / \mathrm{ml}$, respectively. The $\mathrm{B}$ concentrations of $0.01,0.1,1$, 5 and $10 \mu \mathrm{g} / \mathrm{ml}$ in mixed solutions of heavy water $(80$ vol $\%)$ and light water $(20 \mathrm{vol} \%)$ were determined with the relative standard deviations $(n=10)$ of $20,7.5,3.5$, 3.0 and $1.0 \%$, respectively. It was found, furthermore, that the present method could be applied to the determination of other elements. That is, $\mathrm{Si}$ and $\mathrm{Al}$ could also be determined by the use of $\mathrm{Cu}$ as the ISE, and $\mathrm{Mg}$, $\mathrm{Cd}$ and $\mathrm{Mn}$ could be determined by the use of $\mathrm{Cr}$ as the ISE.

(Received September 4, 1989)

\section{Keyword phrases}

determination of traces of $\mathrm{B}$ in heavy water; ICP-AES with internal standardization; analysis of mixed solutions of heavy water and light water. 